\title{
Atlantoaxial pseudoarticulation as a cause of neck pain: case illustration
}

\author{
Andrew B. Boucher, MD, Osama N. Kashlan, MD, Matthew F. Gary, MD, and \\ Daniel Refai, MD
}

Department of Neurosurgery, Emory University, Atlanta, Georgia

https://thejns.org/doi/abs/10.3171/2018.8.SPINE18918

KEYWORDS pseudoarticulation; rudimentary joint; false joint; Bertolotti syndrome; neck pain; cervical spine; atlantoaxial

$\mathrm{P}$ SEUDOARTICULATION in the setting of lumbosacral transitional vertebrae, named Bertolotti syndrome, is present in approximately $12.5 \%$ of the population, may often be confused with other etiologies of lumbosacral back pain, and can be difficult to diagnose. ${ }^{1}$ Anesthetic injections into the pseudoarticulation, also termed a false or rudimentary joint, have a therapeutic effect and can be used as a diagnostic measure to predict who may benefit from surgical intervention in patients in whom conservative therapy fails. ${ }^{2}$ Although well characterized in the lumbosacral spine, pseudoarticulation in the cervical spine has never, to our knowledge, been reported in the literature.

We present the case of a 27-year-old woman who noted neck pain without radicular symptoms for greater than 10 years. After exhaustion of conservative measures, a radiological workup with radiographs, CT scans, and MR images demonstrated a left-sided atlantoaxial false joint, suspected to be a congenital anomaly. This pseudoarticulation's position was medial and posterior to the true left $\mathrm{C} 1-2$ articulation, between the inferior aspect of the $\mathrm{C} 1$ lamina and the superior aspect of the $\mathrm{C} 2$ lamina (Fig. $1 \mathrm{~A}-\mathrm{C})$. The patient received a lidocaine/dexamethasone injection into the false joint, and she experienced significant but temporary pain relief. Therefore, she subsequently underwent a left-sided C1-2 hemilaminectomy for resection of the pseudoarticulation (Fig. 1D). After the immediate postoperative recovery, she reported sustained, complete resolution of her neck pain at the 10-week follow-up. The present case of atlantoaxial pseudoarticulation illustrates a previously unreported etiology of occult neck pain with its associated diagnostic imaging and surgical treatment.

\section{References}

1. Jancuska JM, Spivak JM, Bendo JA: A review of symptomatic lumbosacral transitional vertebrae: Bertolotti's syndrome. Int J Spine Surg 9:42, 2015

2. Jönsson B, Strömqvist B, Egund N: Anomalous lumbosacral articulations and low-back pain. Evaluation and treatment. Spine (Phila Pa 1976) 14:831-834, 1989

\section{Disclosures}

The authors report no conflict of interest concerning the materials or methods used in this study or the findings specified in this paper.

\section{Author Contributions}

Conception and design: all authors. Acquisition of data: Boucher, Kashlan, Refai. Analysis and interpretation of data: Boucher, Kashlan, Refai. Drafting the article: Boucher, Kashlan. Critically revising the article: all authors. Reviewed submitted version of manuscript: all authors. Administrative/technical/ material support: Boucher, Kashlan, Refai. Study supervision: Refai. 
Boucher et al.
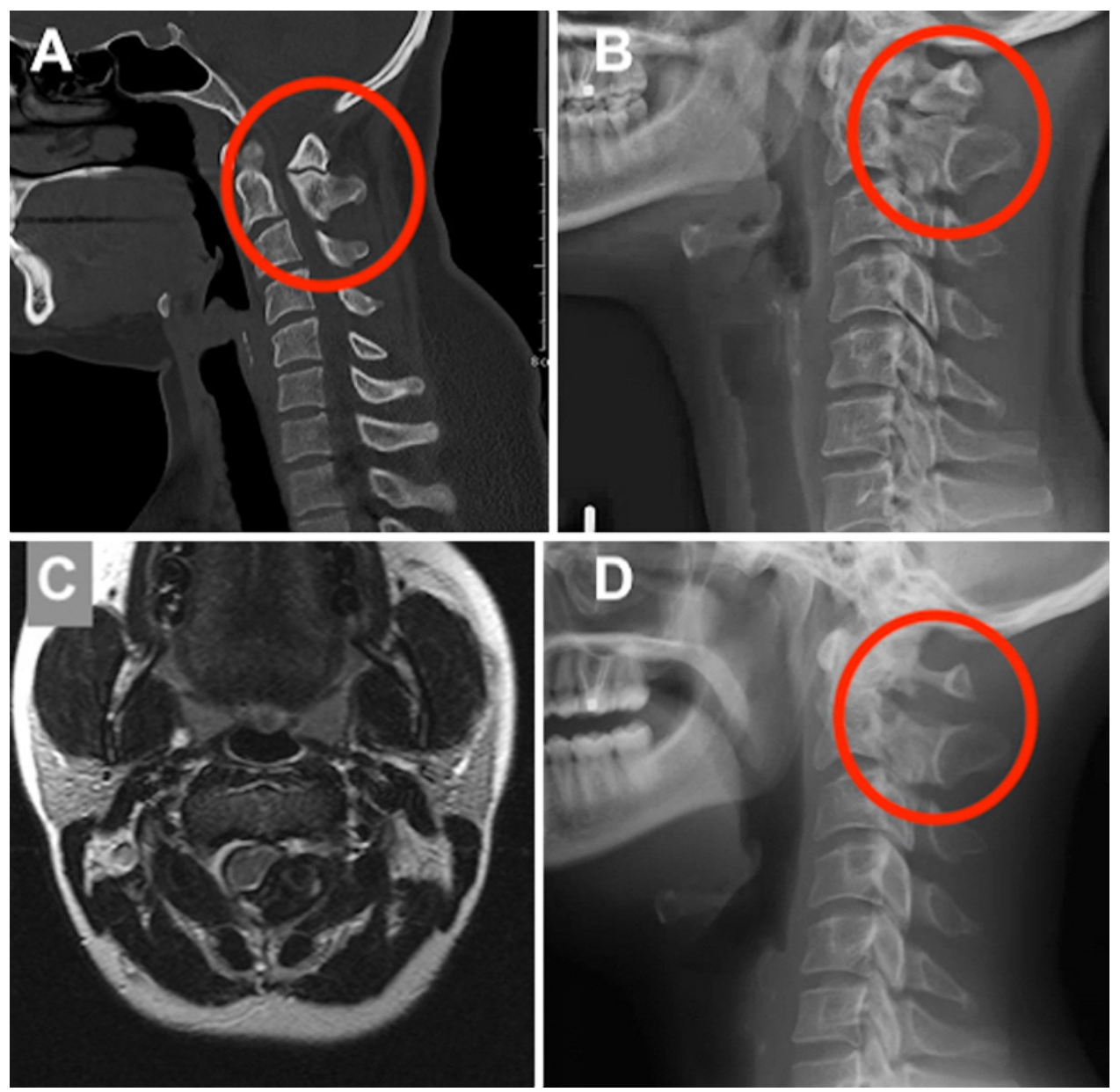

FIG. 1. Left C1-2 hemilaminectomy for removal of left atlantoaxial pseudoarticulation. A: Preoperative sagittal CT scan slightly to the left of midline demonstrates the $\mathrm{C} 1-2$ false joint. B: Preoperative lateral upright radiograph shows the lesion seen on CT (in panel A). Of note, there was no instability on dynamic flexion-extension radiographs. C: Preoperative axial T2 MR image shows the pseudoarticulation with mass effect on the spinal cord. D: Postoperative radiograph illustrates the absence of the resected pseudoarticulation and the remaining normal posterior ring of $\mathrm{C} 1$. The red circles throughout the figure highlight the lesion further. Figure is available in color online only. 